\title{
GIS for data management of environmental surveys, carried out in Biancavilla (CT) superfund experience
}

\author{
S. Bellagamba, F. Paglietti, V. Di Molfetta, F. Damiani \\ \& P. De Simone \\ INAIL - ex ISPESL, Department for Manufacturing Installations and \\ Human Settlements, Italy
}

\begin{abstract}
Biancavilla town has been included by the Italian Environmental Ministry in the Italian Superfund to remediate over the problem of contamination. The contamination is produced by fibrous fluoroedenite, a carcinogen mineral.

Since the 1990s many environmental monitoring campaigns have been made in Biancavilla town by private and public Institutions charged to guarantee the safety of human health and environmental protection, such as Italian INAIL-EXISPESL, National Institute of Health (ISS), Regional Environmental Agency (ARPA), Local Health Agency (AUSL), University of Catania, Circum-Etna Railway.

The Environmental Ministry charged INAIL-EX-ISPESL to create a specific Geographic Information System (GIS) dedicated to the management and consultation of all data collected in Biancavilla town (Catania Sicily), in order to properly handle the large amount of data, in continuous acquisition. The GIS is a tool based on a continuously evolving repository, i.e. an alphanumeric database and digital map updated in real time, through which managing the information about the different monitoring campaigns. GIS Basic function is to associate a geo-referenced location to a descriptive alphanumeric database and to relate such information to events that have happened in the territory. It is also possible to process all data with a complex query associated to geographic position. This paper discusses the GIS, specifically made to collect all monitoring data in Biancavilla town regarding: excavation activities; street cleaning; building operations; human activities. Using this GIS, it is possible to detect trends and increases in the concentration of dangerous fibres in Biancavilla. With this tool it
\end{abstract}


is possible to highlight any exceeding the threshold limit value, concerning the concentration of fibrous airborne particulate. The aim of this paper is to present a useful instrument to quickly identify risk situations and to adopt prevention measures of diffusion of hazardous contaminants. Finally the GIS, using some standardized formats, ensures the continuous updating of data and the information exchange among all subjects involved (institutions, experts, citizens).

Keywords: geographic information system, risk, fluoroedenite, asbestos.

\section{Introduction}

Since the 1990s numerous environmental monitoring campaigns have been conducted in the Municipality of Biancavilla by leading national bodies and/or competent local agencies set up to protect human health and the environment, including INAIL-DIPIA, ISS, ARPA, AUSL, University of Catania, the Municipal Council and Circum-Etnea Railway, due to the detected widespread presence of a carcinogenic fibre similar to asbestos called "fluoro-edenite". The Environment Ministry has included the Municipality of Biancavilla in the 57 National Priority Sites requiring remediation.

To be able to correctly manage the large amount of data obtained from monitoring, which continues to be gathered, regarding the level of environmental contamination present at the site, INAIL-DIPIA has set up an ad hoc GIS (Geographic Information System) dedicated to the handling and consultation of all data collected in the Municipality of Biancavilla (CT).

This GIS makes it possible to associate geo-referencing with monitoring carried out during various activities - e.g. excavation work, street cleaning, building works, etc. - and to gauge in real time any increases in concentrations of harmful fibres in the air and their location.

This paper illustrates, as an example, the use of a GIS dedicated to Biancavilla and seeks to highlight the advantages of using such integrated information management systems.

\section{The NPL site of Biancavilla}

One of the best-known sites in Italy's NPL (National Priority List) is the Municipality of Biancavilla (Catania), a small town of 23,000 inhabitants standing at the foot of Mount Etna, where over the past 20 years there have been about 40 recorded deaths due to pleural mesothelioma, 10 times greater than the national average.

The detected pollutant is a fibrous volcanic amphibole called Fluoro-edenite, a bright yellow fibrous mineral made up of very thin (less than 1 micron in diameter) and relatively long fibres (up to 50-80 microns), which cause pathologies similar to asbestos-related diseases.

The main source of contamination is the broken stone material present in the area, mined up to the year 2000 in the Monte Calvario quarry. Since then, over the past ten years hundreds of logs and thousands of surveys of airborne 
materials have been carried out to assess the extent of contamination and measure concentration values for these fibres in the air.

Analyses have shown that hundreds of samples, both in rocks and airborne, are contaminated by fluoro-edenite, with variable concentrations, often exceeding allowed limits. The Municipality has accordingly been included in the 57 National Priority Sites to be cleaned up.

The Environment Ministry receives technical and scientific support from National Scientific Bodies, including INAIL-DIPIA, in managing emergency shutdown and remediation procedures. In greater detail, the following work phases have been monitored: surfacing of non-asphalted roads, disposal of piles of material, rubble and dust in bags after adequate wetting or treatment with encapsulator products, cessation of quarrying activity and creation of an ad hoc dump.

\section{Methods}

While performing the above activities a total of 1,800 samples of airborne materials were taken from 2000 to 2010, with both environmental and personal sampling, performed by Ispesl, the University of Catania, Arpa Sicilia and private Laboratories on behalf of the Municipality. Acquired data have been filed and managed in a dedicated GIS, including details on:

- date of sampling,

- place of sampling,

- sampling volumes,

- meteorological conditions,

- method of analysis,

- value of detected concentration, expressed in $\mathrm{f} / \mathrm{l}$,

- lower and upper confidence limits,

- analytical methods (SEM or PCOM).

Collected samples derive from specific sampling techniques, drawn up especially for this NPL Site, for both personal and environment sampling, both indoor and outdoor.

The most appropriate instrument for the optimal management of monitoring data has proven to be a computerised database associated with a GIS. The database is used to collect, organise, manage, update and easily consult data, while the GIS allows the entry of data in the local context, in other words on a geographic basis.

This GIS can be consulted by means of queries, making it possible to describe the trends over time of pollution/depollution phenomena and to highlight situations at risk.

The peculiar nature of the GIS is its topological structuring of data management of information based on the mutual spatial relations of various elements, the possibility of conducting analyses on attributes and the possibility of processing geographic data using mathematical algorithms. Algorithms make it possible to combine different levels of information via simple operators, such as overlaying, or complex operators, such as buffering, making it possible to 
create new information levels, associating data so as to identify relations that would otherwise be difficult to detect.

The software used to manage the geographic database is ArcGis 10, produced by Esri, while for the alphanumeric database Microsoft's Access software is used.

In the specific case of the Municipality of Biancavilla the results of samples taken were collected in an ad hoc database, with the construction of interrelated tables and creation of two specific masks, one for the filing of environmental samples, the other for personal samples, to facilitate data entry. A total of 115 environmental sampling points were identified, deriving from monitoring activities performed by INAIL DIPIA, ARPA, the University and private Laboratories on behalf of the Municipality and the newly formed Circum-Etnea Railway. With regard to environmental samplings, about 1,800 records have been entered regarding a period of time of about 10 years (2000-2010).

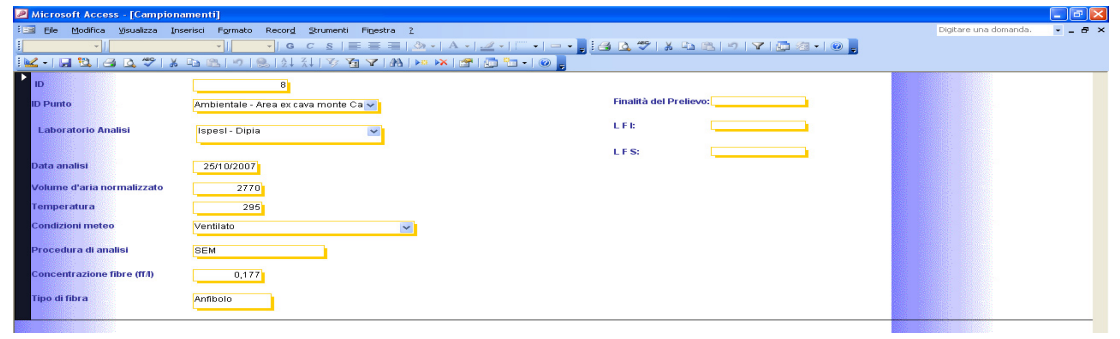

Figure 1: Environmental sampling information mask.

With regard to the monitoring of workers and the exposed population, data on 37 subjects subjected to personal sampling were catalogued. There are about 380 stored records for the period 2008-2010, a period of time for which measurements have been standardised.

Geo-referenced shapefiles with vectorial layers have been included in the GIS:

- $\quad$ sampling points

- municipal grid

- $\quad$ provincial grid

- regional grid

- $\quad$ road and rail network obtained from Teleatlas mapping

- map of population density obtained with Istat data from the population census (2001)

- $\quad$ sensitive receptors (schools, hospitals, etc.)

There are also geo-referenced layers in raster format, such as:

- $\quad$ high-definition IKONOS satellite images and orthophotography

To be entered in the GIS, layers have been geo-referenced in the reference geographic system WGS84 UTM32. The system makes it possible to query the alphanumeric database, view analytical values obtained from samplings on the map and render the various levels of exposure visible in graph form. 


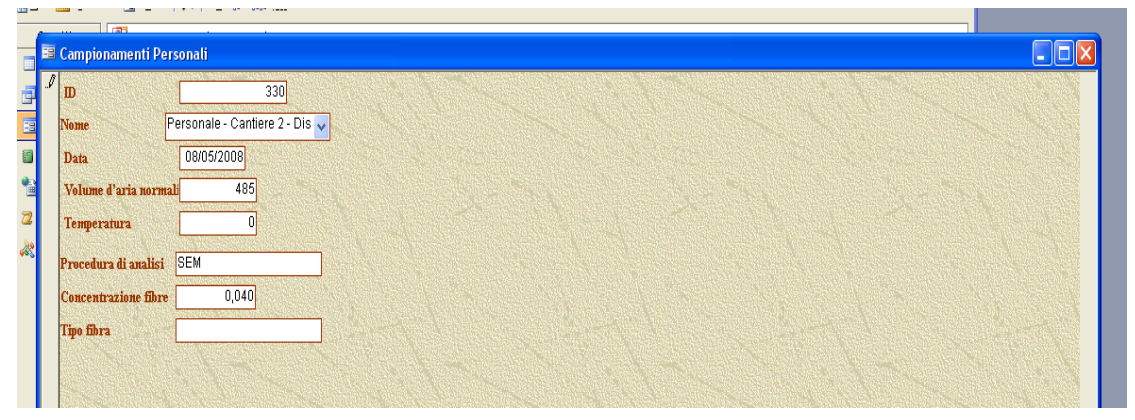

Figure 2: $\quad$ Personal sampling information mask.

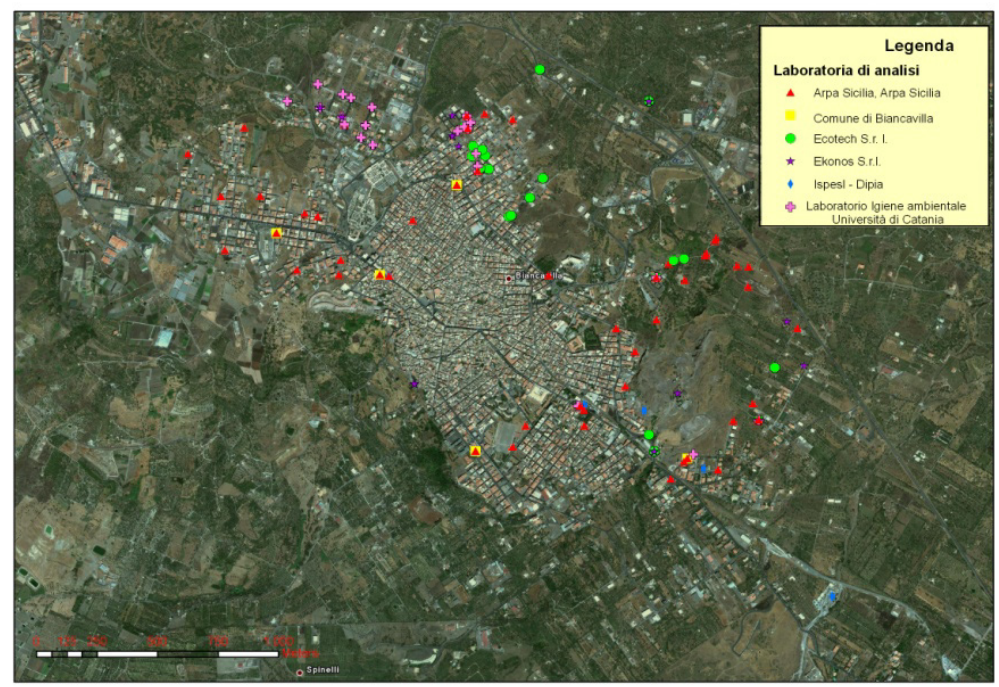

Figure 3: Location of environmental sampling points in the GIS of Biancavilla.

\section{Discussion}

The GIS has made it possible to file analytical data on personal and environmental samplings. Personal samplings were conducted on both remedial and territorial rehabilitation site workers and other categories at risk.

With regard to remediation operators, two-monthly data for the period 20082009-2010 are given, a period in which remediation activities were realized and for which measurements have been standardised. Personal sampling was conducted by drawing a volume of 4801 at a rate of $21 / \mathrm{min}$, with analysis via Phase Contrast Optical Microscopy (PCOM).

The values recorded in that period, illustrated in Fig. 4, showed fibre concentration levels of about $0-0.4 \mathrm{f} / 1$ in 2008 , with a slight increase in more 
recent samplings $(1 \mathrm{f} / \mathrm{l})$, but remaining well below the allowed threshold limit $(100 \mathrm{f} / \mathrm{l})$. Concentration levels, which were also well below the pre-alarm value of $20 \mathrm{f} / 1$, showed that safety procedures adopted with the specific aim of protecting workers' health (adoption of specific PPE, immediate removal of piles of contaminated soil present on the sides of dirt roads for replenishment, wetting with water and encapsulators, washing of incoming and outgoing site vehicles, daily washing of equipment, yards and service areas, etc.) had a positive effect.

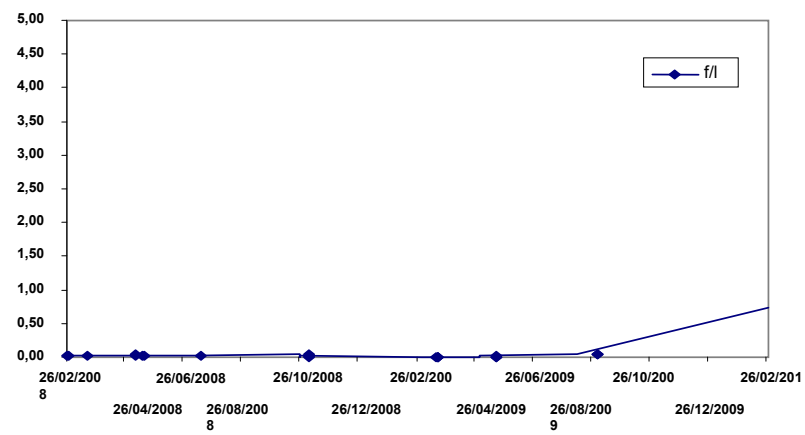

Figure 4: Concentration level of fibres measured from personal sampling (2008-2010) of remedial and territorial rehabilitation site workers.

With regard to the analytical results of personal samplings on other categories at risk, data for 2010 are given, with a data given in graph form on:

- housewives

- traffic police agents

- refuse collectors

- building workers.

The results of analyses conducted over the course of a full year, corresponding to about 300 samples, are illustrated in Figures 5-8.

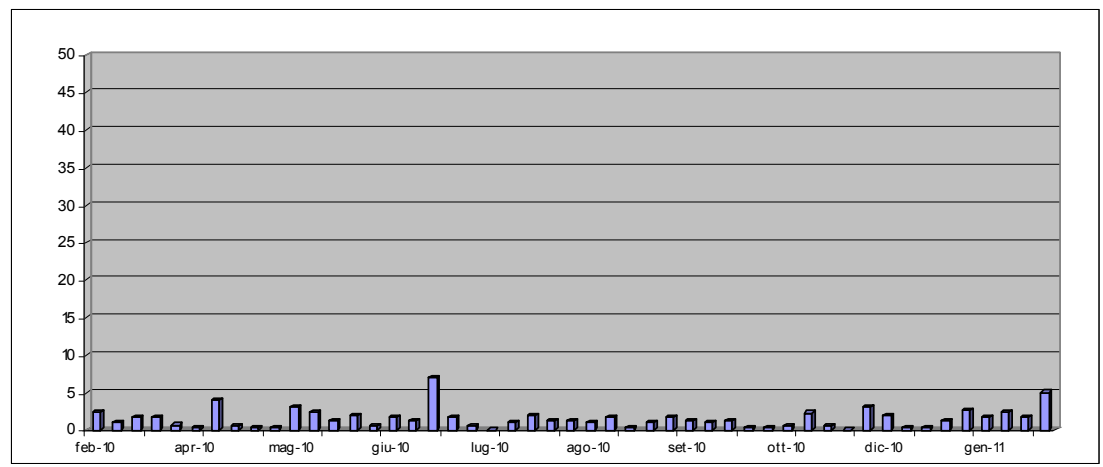

Figure 5: Concentration level of fibres measured from personal sampling of housewives (year 2010). 


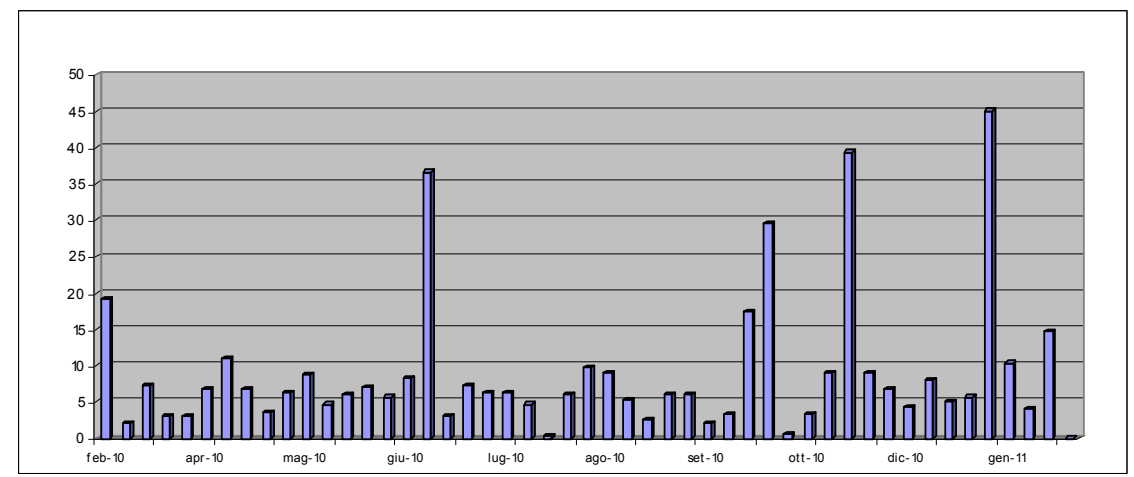

Figure 6: Concentration level of fibres measured from personal sampling of building workers (year 2010).

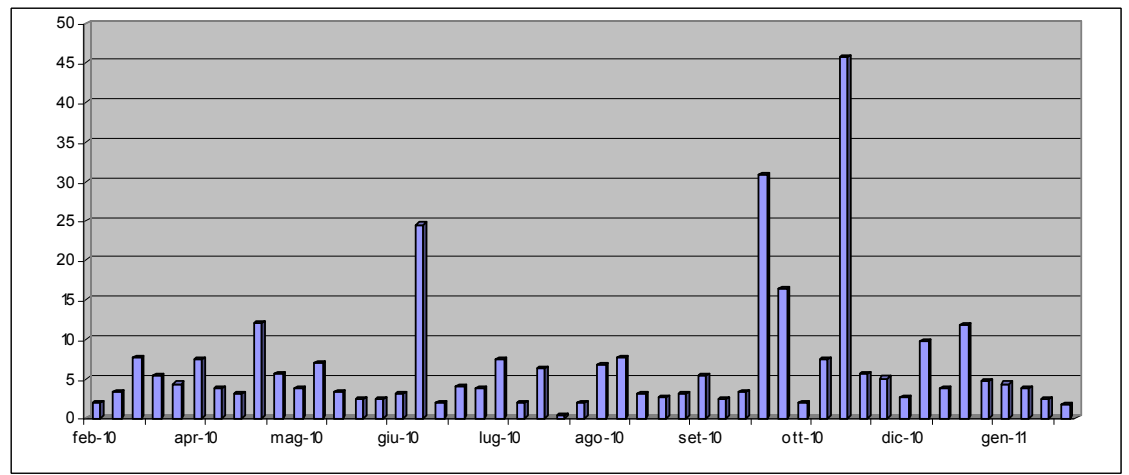

Figure 7: Concentration level of fibres measured from personal sampling of traffic police agents (year 2010).

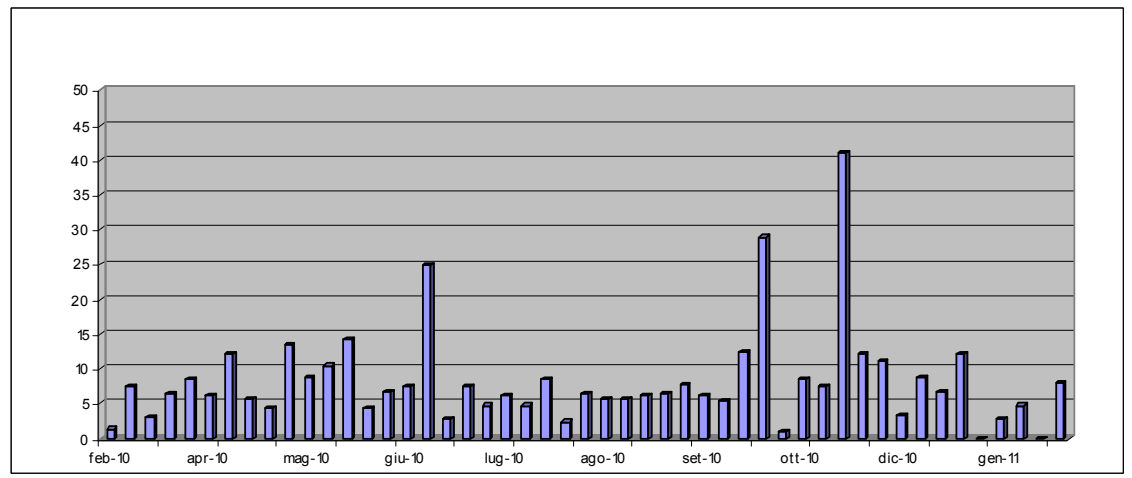

Figure 8: Concentration level of fibres measured from personal sampling of refuse collectors (year 2010). 
It should be noted that in Italy current legislation does not establish a reference limit for personal samplings in living environments. Therefore, data on the concentration of asbestos fibres relative to housewives cannot be referenced to a given TLV. As established by the Italian Environmental Ministry in Italian Superfund, in this case it must respect the exposure threshold of $1 \mathrm{f} / 1$ in an urban environment, as recommended by the document Air Quality Guidelines for Europe (WHO, 2000). It is necessary nonetheless noted that excess values have been recorded with a maximum of 7.06 in the month of July.

With regard to other categories examined (traffic police agents, refuse collectors, and building workers) deemed to be most exposed to this risk, as they perform work activities outdoors, again there is no reference limit for personal samplings in working environments not related to the activities of handling and cleaning up asbestos or items containing asbestos. In the latter case the reference TLV is $100 \mathrm{f} / 1$. Accordingly, and in the same way, in working environments free from direct exposure to asbestos, this reference value is normally used. Below in graph form are the results obtained via PCOM analysis for these three worker categories.

As above shown, in any case, the TLV value has been exceeded.

With regard to environmental sampling (Fig. 9), monitoring data in which the exposure threshold of $1 \mathrm{f} / 1$ in an urban environment, as recommended by the document Air Quality Guidelines for Europe (WHO, 2000), has been exceeded, were analysed. Filed data were processed in graph form, showing 34 cases of excess values for the years 2000, 2008, 2009 and 2010.

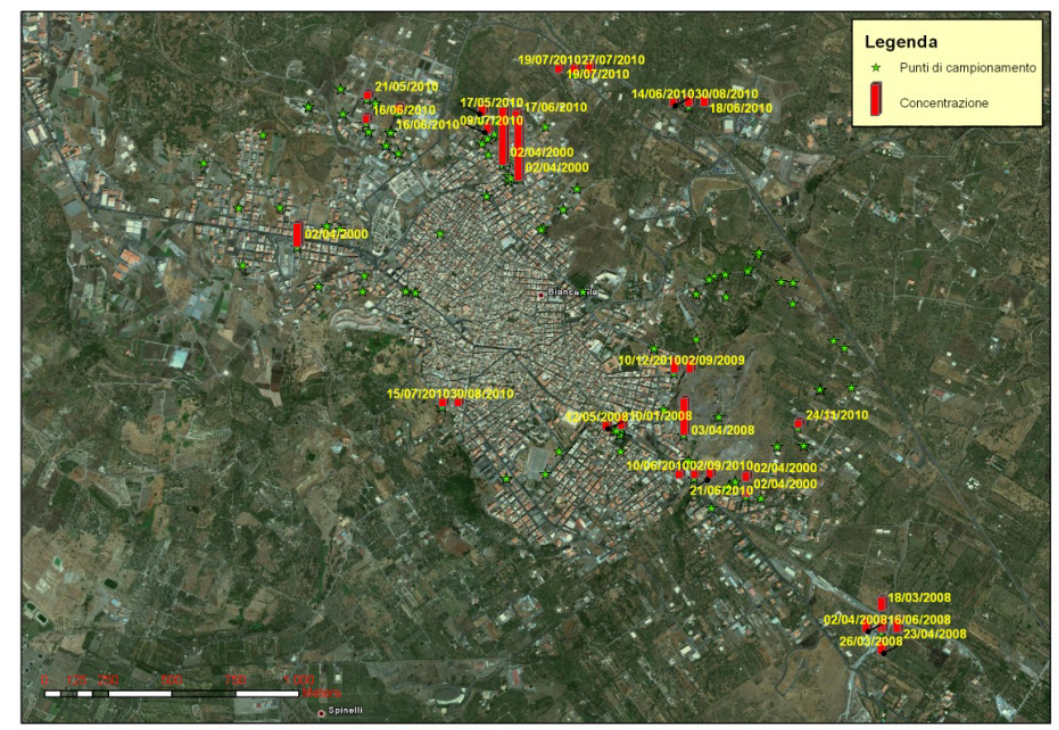

Figure 9: $\quad$ Map of samplings in the municipality of Biancavilla. 
Excess values regarding the year 2000 occurred in the spring/summer period, when there were concentration peaks $>8 \mathrm{f} / 1$ in the month of April.

With regard to 2008 , excess values were recorded in the spring period, with concentrations $>5 \mathrm{f} / \mathrm{l}$ in April.

In the years 2009 and 2010 there were again excess TLV values in the spring/summer period. For these years fibre concentrations were measured at around $2 \mathrm{f} / \mathrm{l}$.

The above highlights a constant increase in risk in the dry period. This conforms to recorded meteorological data, which show in the warmer seasons conditions that facilitate the dispersion in the air of fibres (high winds and dry climate).

Overall data collected from 2000 to 2010 in the database are also given in the graph in Fig. 10, showing a gradual reduction in the concentration of fluoroedenite fibres from values in excess of $8 \mathrm{f} / \mathrm{l}$ to values on average less than $2 \mathrm{f} / \mathrm{l}$. This reduction is the result of a number of remedial activities (closure of quarrying activity, asphalting of town streets, removal of piles of contaminated soil, encapsulation of contaminated plaster in all public buildings, etc.) carried out in the cited NPL Site. The few times the TLV of $1 \mathrm{f} / 1$ has been exceeded have always been seen in conjunction with the moving of contaminated soil.

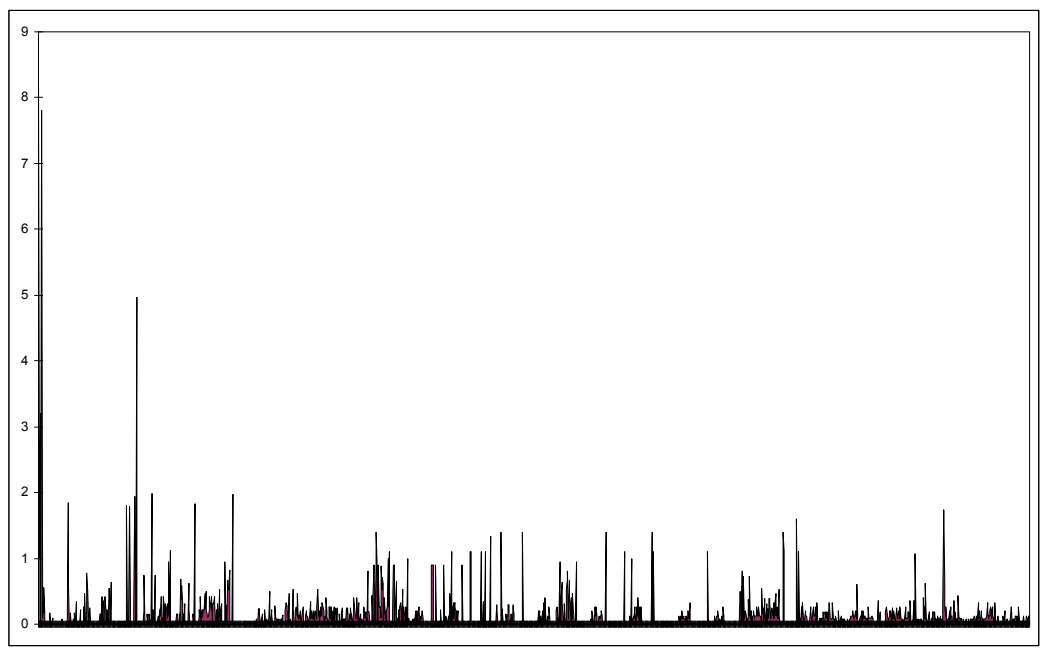

Figure 10: Results of samplings carried out in the Municipality of Biancavilla $(2000-2010)$.

From the map of Fig. 11 three town areas at greatest risk are identified:

1. the area situated in the extreme north and extreme south of the town, both devoid of asphalted surfaces (excess values in year 2000) and still today partially with dirt roads, with soil contaminated by fluoro-edenite; 
2. the area around the Monte Calvario quarry where there are outcrops of contaminated rocks exposed to meteorological phenomena and a connected municipal dump for contaminated soils;

3. the area to the south-east of the town, close to the municipal border between Biancavilla and the municipality of Santa Maria di Licodia, where there are worksite areas of the newly formed Circum-Etnea Railway, with trucks and service vehicles entering and leaving contaminated tunnels.

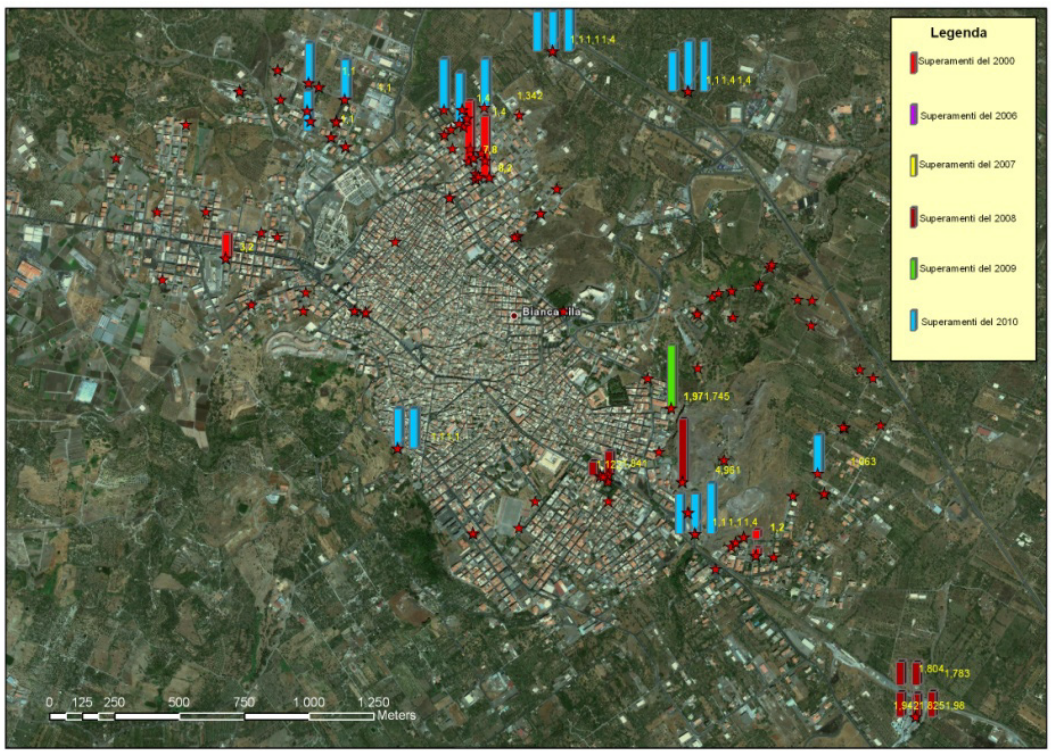

Figure 11: Exceeding of threshold limits: results of samplings carried out in the Municipality of Biancavilla (2000-2010).

\section{Conclusions}

The example of a GIS specially created for the Municipality of Biancavilla has illustrated the advantages of using this system to manage analytical data. In particular, this instrument makes it possible for authorities set up to protect workers and the exposed population to quickly pinpoint critical zones and easily consult data, thanks to implementation procedures and automated analysis. This has enabled competent local supervisory authorities (AUSL and ARPA) and the municipal administration to take suitable precautionary measures for both exposed workers and for urban living environments.

This experiment in the sphere of a dedicated GIS has also illustrated the advantages of using these computerised technologies, which have proved to be a valid tool for quickly identifying situations of environmental danger, and consequently an indispensable tool when taking precautionary measures. 


\section{References}

[1] F. Paglietti, S. Bellagamba, S. Malinconico, V. Di Molfetta, P. De Simone, $M$. Giangrasso "Asbestos presence on the Italian National Territory: Progress Report on Mapping and Remediation Activity" ASTM Johnson Conference: Critical Issues in Monitoring Asbestos, (Vermont, USA), 2008

[2] Gianfagna A., Oberti R., "Fluoro-edenite from Biancavilla (Catania, Sicily, Italy): crystal chemistry of a new amphibole end-member", (2001). American Mineralogist. vol. 86, pp. 1489-1493..

[3] F. Paglietti, S. Malinconico, F. Damiani, P. De Simone "Natural Asbestos Contamination: Biancavilla's Case" - ASTM 2008 Johnson Conference: Critical Issues in Monitoring Asbestos, (Vermont, USA)

[4] F. Paglietti, V. Di Molfetta, S. Malinconico, M. Giangrasso, S. Bellagamba, F. Damiani. Italian Asbestos Mapping. World Asbestos Conference October 1-3 2009. 